\title{
TANTALUM THIN FILM CAPACITORS WITH VARIOUS TYPES OF COUNTERELECTRODES
}

\author{
G. P. FERRARIS and R. MAY \\ G. T. E Telecomunicazioni, S.T.Av, 20060-Cassina de' Pecchi, Milan, Italy.
}

(Received July 15, 1979)

\begin{abstract}
Capacitors have been prepared from $\mathrm{N}_{2}$-doped, triode sputtered Tantalum films by conventional anodization and photolitographic techniques.

$\mathrm{NiCr}-\mathrm{Au}, \mathrm{Ta}-\mathrm{Ti}-\mathrm{Pd}-\mathrm{Au}, \mathrm{Ta}-\mathrm{NiCr}-\mathrm{Pd}-\mathrm{Au}$ have been used as counterelectrode materials and the a.c. and d.c. properties of the capacitors have been compared.

It has been found that a doped Ta thin layer deposited by sputtering between the dielectric and the top electro de does not negatively affect the capacitors characteristics; moreover, a thermal treatment at temperatures as high as $350^{\circ} \mathrm{C}$ can be tolerated.

If the Ta film deposited after the dielectric formation is used for resistive elements, a fully compatible R-C process is obtained which requires only two vacuum deposition cycles and four photolithographic steps.
\end{abstract}

\section{INTRODUCTION}

The possibility of matching very closely the temperature characteristics of thin film Ta capacitors and resistors, makes them a very attractive proposition in high precision, high stability RC circuits. In recent years, capacitor properties have been improved by $\mathrm{N}_{2}$ doping the Ta base film ${ }^{1,2,3}$ at various atomic percentages, giving better yield, temperature and life stability, and lower dissipation factors when compared to first generation capacitors based on pure $\beta$-Ta films. ${ }^{4,5}$ Moreover, $\mathrm{N}_{2}$-doped Ta capacitors can withstand exposure to high temperatures, such as those occurring when $\mathrm{R}$ and $\mathrm{C}$ are obtained on the same substrate: also, thermal treatment can be included in the fabrication process to improve capacitor properties. ${ }^{4,6,7}$

Almost exclusively, $\mathrm{NiCr}-\mathrm{Au}$ has been used as the counterelectrode metallization, although sputtered $\mathrm{NiCr}-\mathrm{Pd}$ with subsequent selective gold plating has been used for the counterelectrodes of critical RC active filters. ${ }^{8}$

In the present paper the characteristics of nitrogen doped capacitors with $\mathrm{Ta}$ based triode sputtered top electrodes $\left(\mathrm{TaO}_{x} \mathrm{~N}_{y}-\mathrm{NiCr}-\mathrm{Pd}-\mathrm{Au}\right.$ and $\mathrm{TaO}_{x} \mathrm{~N}_{y}-\mathrm{Ti}-\mathrm{Pd}-\mathrm{Au}$ ) are compared to those of $\mathrm{NiCr}$-Au standard capacitors. The excellent properties of the $\mathrm{N}_{2}$-doped capacitors are not negatively affected by the presence of the $\mathrm{Ta}-$ oxinitride layer at the dielectric interface.

\section{PREPARATION OF CAPACITORS AND TEST EQUIPMENT}

The Tantalum base electrode films were deposited by triode sputtering from a $60 \mathrm{~mm}$ diameter Ta target in a stainless steel, oil diffusion pumped chamber; the sputtering system has been described in more detail in a previous paper, ${ }^{9}$ the only difference being the substrate holder, which in the present experiments was of the planetary type, bearing $302^{\prime \prime} \times 2^{\prime \prime}$ square substrates.

Both Corning Glass 7059 and glazed alumina were used and prior to deposition of $\alpha-\mathrm{Ta}$ an etch-stop layer of $3000 \AA$ Tantalum pentoxide was reactively deposited onto the substrates in an $\mathrm{Ar}$ and $\mathrm{O}_{2}$ atmosphere. Pure nitrogen was then released in the chamber at flow rates ranging from 0 to $1.6 \mathrm{sccm}$ and, after some minutes of presputtering, nitrogen doped Ta was deposited for 40 minutes at a deposition rate of $110 \AA / \mathrm{min}$. Thickness, sheet resistance, TCR and thermoelectric power were measured on test samples.

Other substrates were processed into capacitors by anodization to $180 \mathrm{~V}$ or $230 \mathrm{~V}$ in $0.01 \% \mathrm{wt}$. aqueous solution of citric acid at room temperature. After reaching the forming voltage, a soak time of 1 hour was allowed for all samples. Photoresist was used to delineate the dielectric pattern during the anodization process.

Different types of counterelectrodes were then 
sputter deposited onto the substrates in the same triode sputtering system used for the Ta base electrode: $\mathrm{NiCr}(200 \AA)-\mathrm{Au}(3000 \AA), \mathrm{TaO}_{x} \mathrm{~N}_{y}$ $(300 \AA)-\mathrm{NiCr}(200 \AA)-\mathrm{Pd}(2800 \AA)-\mathrm{Au}(3000 \AA)$ and $\mathrm{TaO}_{x} \mathrm{~N}_{y}(300 \AA)-\mathrm{Ti}(500 \AA)-\mathrm{Pd}(2800 \AA)-\mathrm{Au}$ $(3000 \AA)$. Nichrome was sputtered from a 80:20 $\mathrm{NiCr}$ target and $\mathrm{Ta}-$ oxinitride was reactively deposited in an $\mathrm{Ar}-\mathrm{O}_{2}-\mathrm{N}_{2}$ atmosphere.

On each substrate, four arrays of 18 capacitors, each $0.1 \mathrm{~cm}^{2}$ of active area, were patterned by photolitho techniques and some samples were thermally treated at $250,300,350^{\circ} \mathrm{C}$ in air. For voltage step-stress testing and accelerated life tests, leads were soldered on after separating the individual circuits.

Capacitance (C) and dissipation factor $(\tan \delta)$ were measured with a Hewlett-Packard 4270A automatic bridge at $1 \mathrm{kHz}$ and TCC calculated from values measured at $15^{\circ} \mathrm{C}$ and $85^{\circ} \mathrm{C}$.

Some measurements to establish accurately the dependence on temperature and frequency of $\mathrm{C}$ and $\tan \delta$ were performed with an ESI manual bridge.

For dc insulation resistance measurements, a G.R. 1864 Megohmmeter was employed.

\section{EXPERIMENTAL RESULTS}

\subsection{Effect of Nitrogen Doping}

The electrical properties of triode sputtered, $4400 \AA$ thick Ta films are summarized in Table I. With no intentional nitrogen doping, the values of $\rho=202 \mu \mathrm{ohm} . \mathrm{cm}$ and TCR $=-130 \mathrm{ppm} /{ }^{\circ} \mathrm{C}$ can be taken as for a $\beta-\mathrm{Ta}$ crystalline structure. Nitrogen doping at increasing rates first causes the resistivity to fall $\left(65 \mu \mathrm{ohm} . \mathrm{cm}\right.$ at $\left.0.6 \mathrm{sccm} \mathrm{N} \mathrm{N}_{2}\right)$ and the TCR to rise sharply $\left(+760 \mathrm{ppm} /{ }^{\circ} \mathrm{C}\right.$ at $\left.0.6 \mathrm{sccm} \mathrm{N}_{2}\right)$. These values are typically referred to a bcc structure. Between 0.6 and $1.6 \mathrm{sccm} \mathrm{N}$, TCR steadily decreases to $+160 \mathrm{ppm} /{ }^{\circ} \mathrm{C}$, where a corresponding resistivity of $133 \mu \mathrm{ohm} . \mathrm{cm}$ has been measured.

The nitrogen atomic content has not been determined by direct analysis. Because of differences in deposition systems and parameters only a rough estimate is possible from the literature, ${ }^{6,10}$ based on TCR and resistivity. The dielectric constant of anodic oxide grown on these films can also be taken into account.

About 15 at \% of $\mathrm{N}_{2}$ has been estimated for Ta films sputtered at $1.2 \mathrm{sccm} \mathrm{N}_{2}$, from which the capacitors for most experiments described in this paper were obtained.
TABLE I

Electrical properties of $\mathrm{N}_{2}$-doped Ta films

\begin{tabular}{lllll}
\hline $\begin{array}{l}F\left(\mathrm{~N}_{2}\right) \\
(\mathrm{sccm})\end{array}$ & $\begin{array}{l}t \\
(\AA)\end{array}$ & $\begin{array}{l}R_{s} \\
(\mathrm{ohm} / \mathrm{sq} .)\end{array}$ & $\begin{array}{l}\rho \\
(\mu \mathrm{ohm} . \mathrm{cm})\end{array}$ & $\begin{array}{l}\text { TCR } \\
\left(\mathrm{ppm} /{ }^{\circ} \mathrm{C}\right)\end{array}$ \\
\hline 0. & 3900 & 5.18 & 202 & -133 \\
0.6 & 4200 & 1.51 & 63 & 760 \\
0.8 & 4300 & 1.75 & 75 & 590 \\
1.0 & 4350 & 1.99 & 86 & 435 \\
1.2 & 4400 & 2.27 & 100 & 330 \\
1.4 & 4400 & 2.66 & 117 & 238 \\
1.6 & 4400 & 3.03 & 133 & 163 \\
\hline
\end{tabular}

The effect of doped Ta composition on capacitor properties has been analyzed for capacitors anodized to $230 \mathrm{~V}$ with sputtered $\mathrm{NiCr}$ counterelectrodes.

An almost linear decrease of capacitance density has been found with increasing nitrogen in the sputtering atmosphere; this is shown in Figure 1 where the normalized capacitance has been plotted against $\mathrm{N}_{2}$ flow rate. Dissipation factors and TCC are virtually insensitive to nitrogen doping of base electrodes over the concentration range examined: $2.2 \times 10^{-3}$ and $235 \mathrm{ppm} /{ }^{\circ} \mathrm{C}$ are typical figures, the only exception being nondoped samples which exhibited higher values for both parameters of $3.5 \times 10^{-3}$ and $560 \mathrm{ppm} /{ }^{\circ} \mathrm{C}$ respectively. This is most probably due to temperature rise during sputtering the counterelectrode, as confirmed in a separate experiment where vacuum evaporation was used instead of sputtering.

Different capacitor properties begin to emerge under thermal treatment, as shown in Figures 2 and 3 and the effects of nitrogen content become more

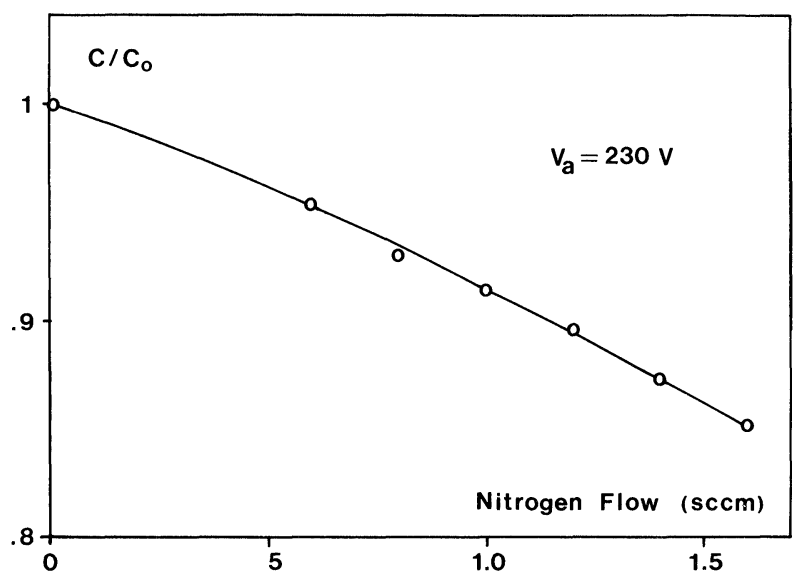

FIGURE 1 Normalized capacitance vs. nitrogen doping of Ta base electrode, anodization voltage $230 \mathrm{~V}$. 


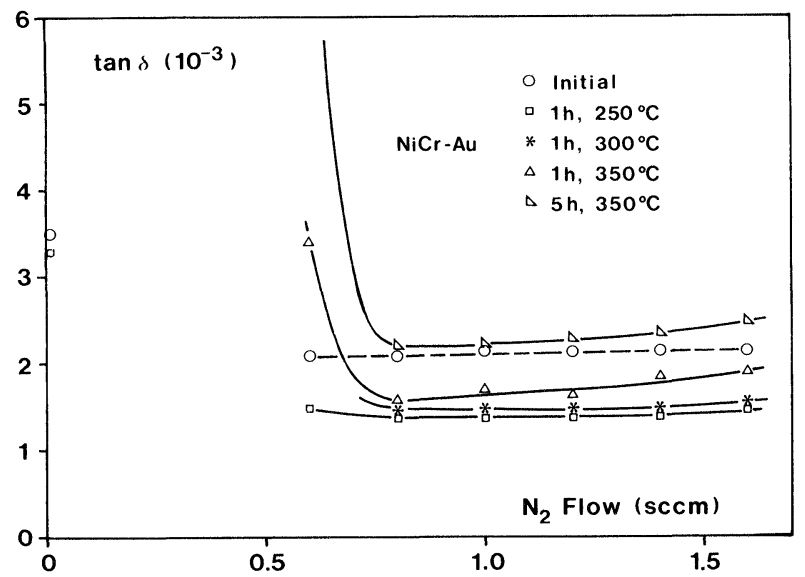

FIGURE 2 Dissipation factor of thermally treated $230 \mathrm{~V}$ capacitors with $\mathrm{NiCr}-\mathrm{Au}$ counterelectrode.

pronounced as heating time and temperature are increased.

At $250^{\circ} \mathrm{C}$ for 1 hour, heat treated capacitors show uniform reductions of $\tan \delta$ and TCC to $1.4 \times 10^{-3}$ and $150 \mathrm{ppm} /{ }^{\circ} \mathrm{C}$, regardless of $\mathrm{N}_{2}$ concentration, and no variations occur after 5 hours.

At $350^{\circ} \mathrm{C}$, minimum TCC and $\tan \delta$ occur between 0.8 and $1.0 \mathrm{sccm}$ flow rate, and both parameters increase with heat treatment time. After 5 hours, capacitors fabricated from low-doped bcc $\mathrm{Ta}$ $\left(0.6 \mathrm{sccm} \mathrm{N}_{2}\right)$ are heavily degraded (TCC $=1100$ $\mathrm{ppm} /{ }^{\circ} \mathrm{C} \tan \delta=10^{-2}$ ), while those sputtered at 0.8 to $1.2 \mathrm{sccm} \mathrm{N}_{2}$ still have a TCC lower than

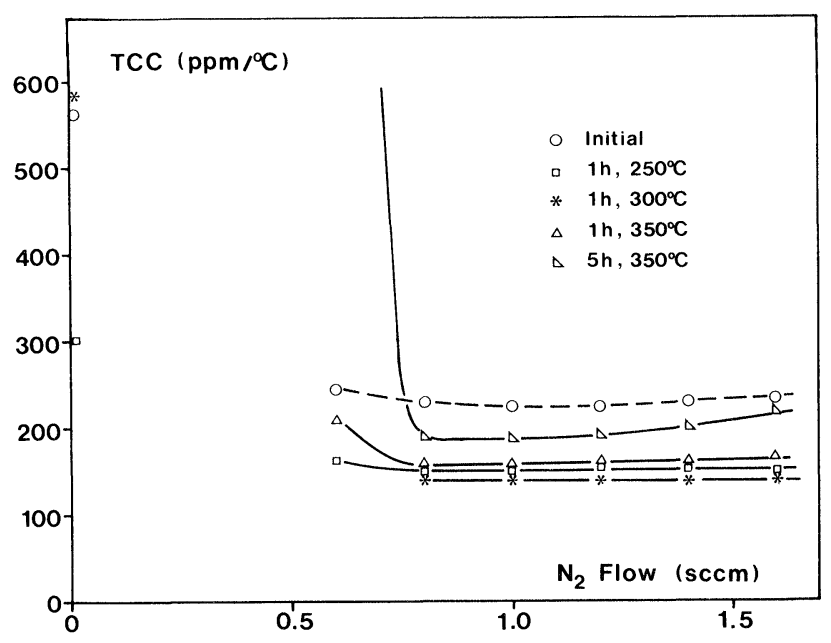

FIGURE 3 Terinperature coefficient of capacitance between 23 and $85^{\circ} \mathrm{C}$ of capacitors as in Figure 2.

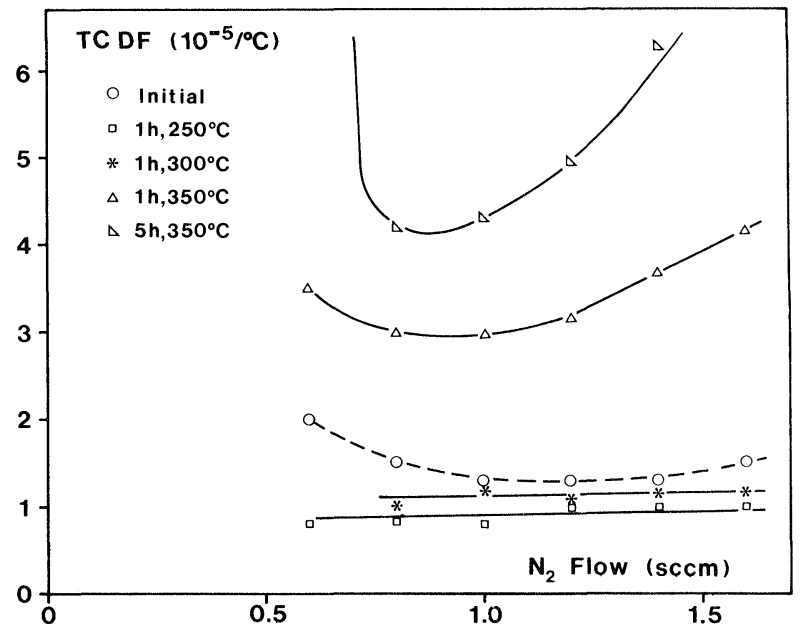

FIGURE 4 Temperature coefficient of dissipation factor between 23 and $85^{\circ} \mathrm{C}$ of capacitors as in Figure 2.

$200 \mathrm{ppm} /{ }^{\circ} \mathrm{C}$ and $\mathrm{a} \tan \delta$ of about 0.0022 , showing that they are very resistant to thermal treatment.

The temperature dependence of the dissipation factor has been examined by measurements at 25 and $85^{\circ} \mathrm{C}$. In this case also the dependence on nitrogen content becomes evident at the highest stabilization temperature: a minimum value of TCDF $=1 \times 10^{-5} /{ }^{\circ} \mathrm{C}$ has been observed for capacitors treated at $250^{\circ} \mathrm{C}$, while $1 \mathrm{~h}$ at $350^{\circ} \mathrm{C}$ is sufficient to shift this parameter up to $3 \times 10^{-5} /{ }^{\circ} \mathrm{C}$ (Figure 4 ).

\subsection{Effect of Counterelectrode}

Additional substrates were collectively processed by sputtering $4000 \AA$ of $\alpha$-Ta at a nitrogen flow rate of $1.2 \mathrm{sccm}$ and subsequent anodization at $180 \mathrm{~V}$. These were then split into three groups and capacitors were fabricated with three different types of top electrode, $\mathrm{NiCr}-\mathrm{Au}, \mathrm{Ta}-$ oxinitride- $\mathrm{NiCr}-\mathrm{Pd}-\mathrm{Au}$, and $\mathrm{Ta}-$ oxinitride-Ti-Pd-Au. The $\mathrm{Ta}$-oxinitride layer, about $300 \AA$ thick, has resistivity $330 \mu \mathrm{ohm} . \mathrm{cm}$ and TCR $-150 \mathrm{ppm} /{ }^{\circ} \mathrm{C}$. The cumulative distributions of capacitance at $23^{\circ} \mathrm{C}$ and $1 \mathrm{kHz}$ are shown in Figure 5.

The dissipation factor at room temperature is not affected by the structure of counterelectrode employed; mean values of $1.4,1.6,1.5 \times 10^{-3}$ were measured on samples of the three types.

Leakage current is an important parameter to evaluate Ta capacitor quality; $50 \mathrm{~V}$ dc was applied with the lower electrode positive and insulation resistance was measured after 30 seconds. 
TABLE II

Leakage current measurements

\begin{tabular}{llllll}
\hline Top electrode & $\begin{array}{l}\text { Number } \\
\text { of cap. }\end{array}$ & $\begin{array}{l}\text { Number } \\
\text { of shorts }\end{array}$ & $\begin{array}{l}\text { Median } \\
I_{l}\end{array}$ & $\begin{array}{l}90 \% \\
I_{l}\end{array}$ & $\begin{array}{l}\text { Yield } \\
I_{l}<2 \mathrm{~A} / \mathrm{F}\end{array}$ \\
\hline $\mathrm{NiCr}-\mathrm{Au}$ & 102 & 4 & $0.22 \mathrm{nA}$ & $0.5 \mathrm{nA}$ & $100 . \%$ \\
$\mathrm{TaO}_{x} \mathrm{~N}_{y}-\mathrm{NiCr}-\mathrm{Pd}-\mathrm{Au}$ & 120 & 4 & $0.5 \mathrm{nA}$ & $\begin{array}{l}2 . \\
\mathrm{nA}\end{array}$ & $98.3 \%$ \\
$\mathrm{TaO}_{x} \mathrm{~N}_{y}-\mathrm{Ti}-\mathrm{Pd}-\mathrm{Au}$ & 120 & 3 & $0.5 \mathrm{nA}$ & $2 . \mathrm{nA}$ & $100 . \%$ \\
\hline
\end{tabular}

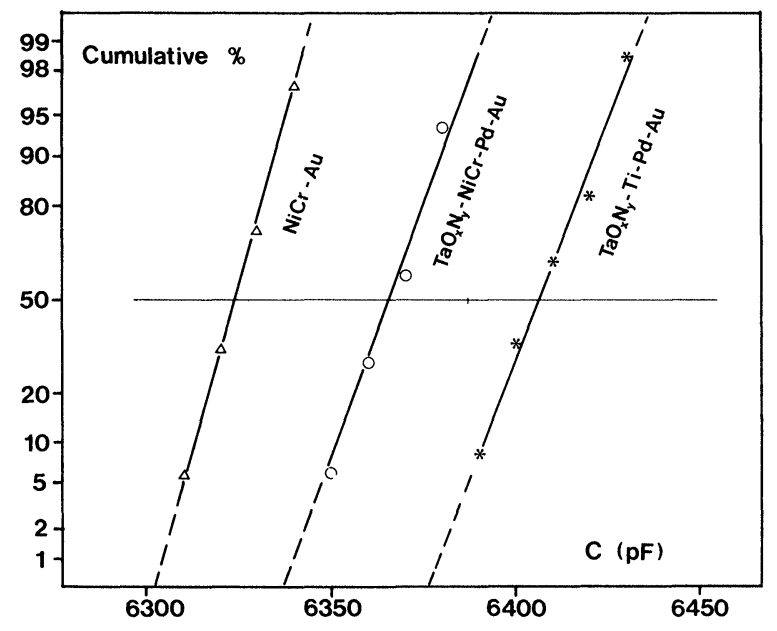

FIGURE 5 Cumulative distributions of capacitance for different types of counterelectrode.

No capacitor with a $\mathrm{NiCr}$ counterelectrode exceeded a limiting value of $13 \mathrm{nA}$ except about $4 \%$ which broke down under the test voltage. The median value is $0.22 \mathrm{nA}$.

Leakage currents of capacitors with Ta oxinitride based counterelectrodes are generally higher and more dispersed. No differences were found between $\mathrm{Ta}-\mathrm{NiCr}-\mathrm{Pd}-\mathrm{Au}$ and $\mathrm{Ta}-\mathrm{Ti}-\mathrm{Pd}-\mathrm{Au}$, both having a median value of $0.5 \mathrm{nA}$ and this is valid for all electrical parameters considered in this paper.

The results of leakage current measurements are shown in Table II.

The effects of high temperature treatment on capacitor properties can be summarized as follows.

Very small negative capacitance variations, less than $-0.15 \%$, are observed for Ta based counterelectrode capacitors which received heat treatment at $300^{\circ} \mathrm{C}$, and even after 1 hour at $350^{\circ} \mathrm{C}$ this type of capacitor exhibited a median capacitance shift of $0.28 \%$, mean deviation of $0.02 \%$. A larger $\Delta \mathrm{C} / \mathrm{C}$ has been measured on $\mathrm{NiCr}-\mathrm{Au}$ capacitors: $1 \%, 1.1 \%$ and $1.5 \%$ for $1 \mathrm{~h}$ at $300^{\circ} \mathrm{C}, 3 \mathrm{~h}$ at $300^{\circ} \mathrm{C}$ and $1 \mathrm{~h}$ at $350^{\circ} \mathrm{C}$ respectively.

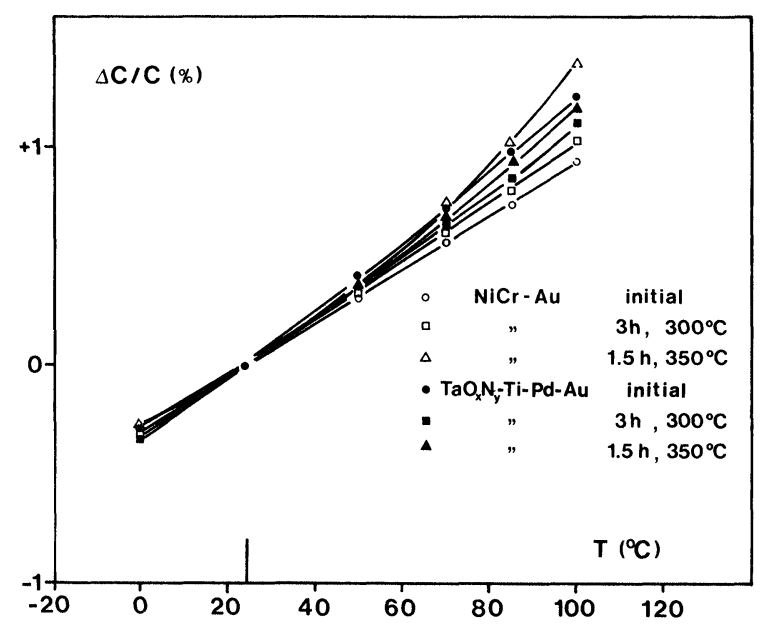

FIGURE 6 Temperature dependence of capacitance for treated and untreated capacitors.

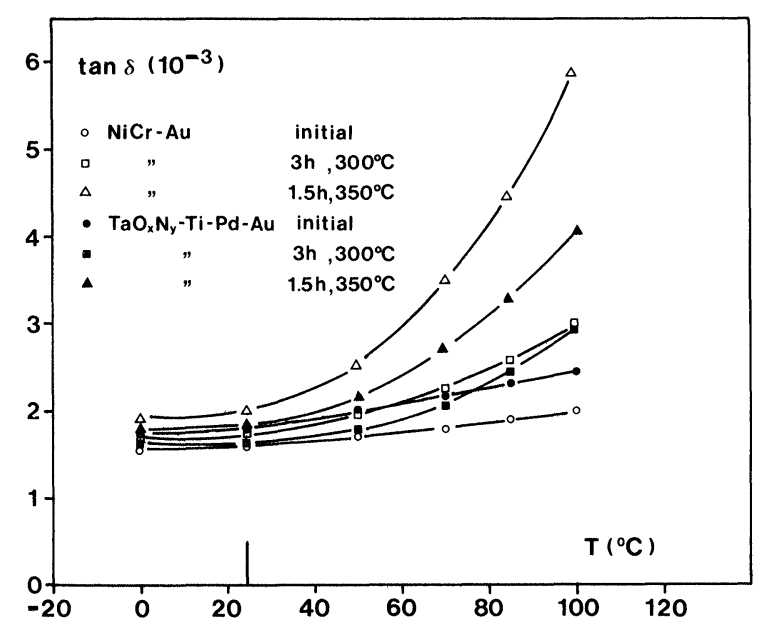

FIGURE 7 Temperature dependence of dissipation factor.

Dissipation factors at room temperature and TCC are consistent at $1.6 \times 10^{-3}$ and 145 to $150 \mathrm{ppm} /{ }^{\circ} \mathrm{C}$ respectively after 1 hour at $300^{\circ} \mathrm{C}$ and small variations occur after prolonged treatment. $\mathrm{NiCr}-\mathrm{Au}$ capacitors show a larger dependence of $\tan \delta$ on 


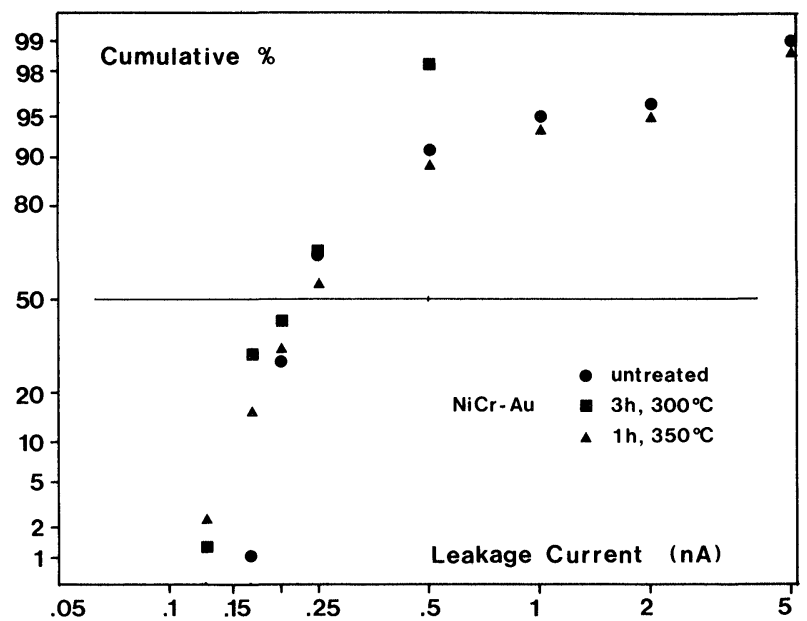

FIGURE 8 Cumulative distribution of leakage current for $\mathrm{NiCr}-\mathrm{Au}$ counterelectrode capacitors.

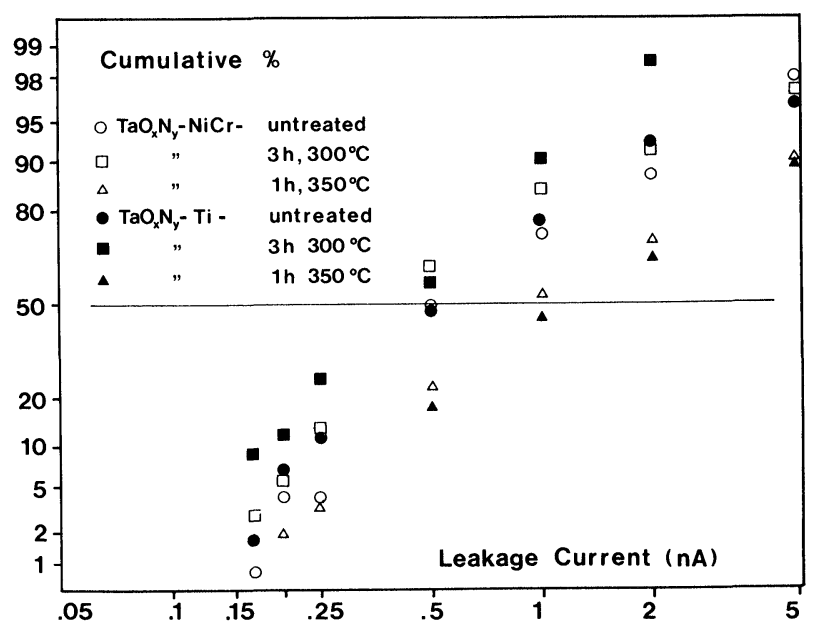

FIGURE 9 Cumulative distribution of leakage current for capacitors with $\mathrm{Ta}$ oxinitride $\mathrm{NiCr}-\mathrm{Pd}-\mathrm{Au}$ and $\mathrm{Ta}$ oxinitride $\mathrm{Ti}-\mathrm{Pd}-\mathrm{Au}$ counterelectrode.

temperature when heat treated at $350^{\circ} \mathrm{C}$, as shown in Figures 6 and 7.

The leakage current of Ta counterelectrode capacitors is somewhat degraded with high temperature treatment, in contrast to $\mathrm{NiCr}$ capacitors whose insulation resistance is practically unchanged even after 5 hours at $350^{\circ} \mathrm{C}$. This situation is shown in Figures 8 and 9 where the cumulative distributions of 1.c. for treated and untreated samples are plotted.

\subsection{Voltage Step-stress Tests}

For preliminary evaluation of capacitor reliability, 12 minute voltage step-stress tests at $85^{\circ} \mathrm{C}$ were carried out on capacitors with the three types of counterelectrode, before and after thermal stabilization at 300 and $350^{\circ} \mathrm{C}$. An important point was to establish whether the leakage current degradation, induced by the thermal treatment on Ta counterelectrode capacitors, yielded lower breakdown voltages and thus potential low reliability.

The distribution of failure voltages for treated and untreated capacitors is shown in Figures 10 and 11.

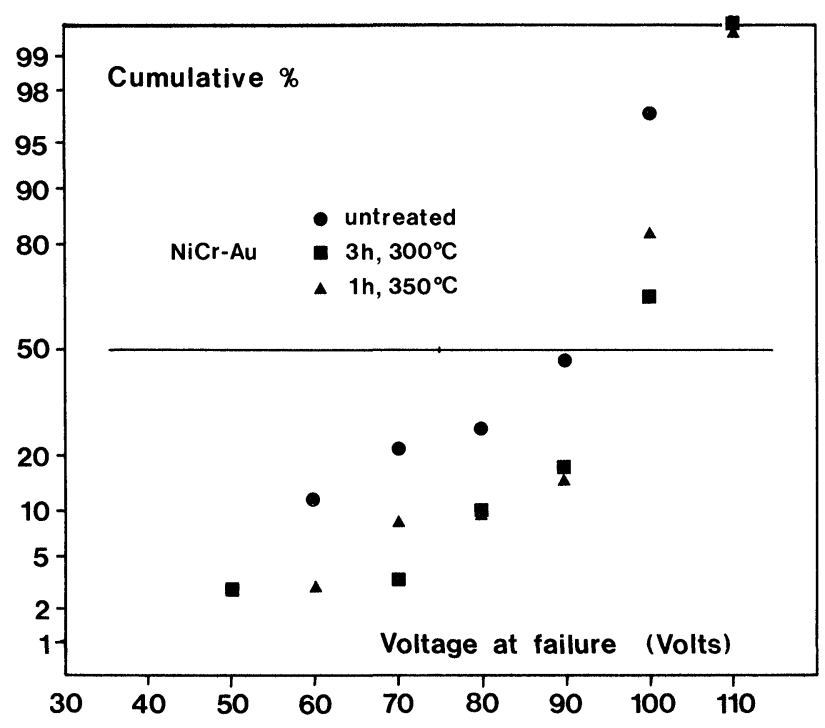

FIGURE 10 Step stress failures at $85^{\circ} \mathrm{C}$ of $\mathrm{NiCr}-\mathrm{Au}$ counterelectrode capacitors.

All groups tested exhibit an average break-down voltage of between 90 and $100 \mathrm{~V}$, regardless of the counterelectrode and stabilization treatment; note that unheated $\mathrm{NiCr}$ capacitors show the lowest mean breakdown voltage of about $90 \mathrm{~V}$.

These values are comparable to previously published results ${ }^{3,6}$ for nitrogen doped, $230 \mathrm{~V} \mathrm{Ta}$ film capacitors, if the dielectric thickness is taken into account.

D.c. bias accelerated life tests at $85^{\circ} \mathrm{C}$ are in progress.

Results after 2000 hours with $50 \mathrm{~V}$ applied show 8 to $13 \%$ failures on $300^{\circ} \mathrm{C}$ heat treated capacitors, related more to the fabrication lot than to the counterelectrode structure. 


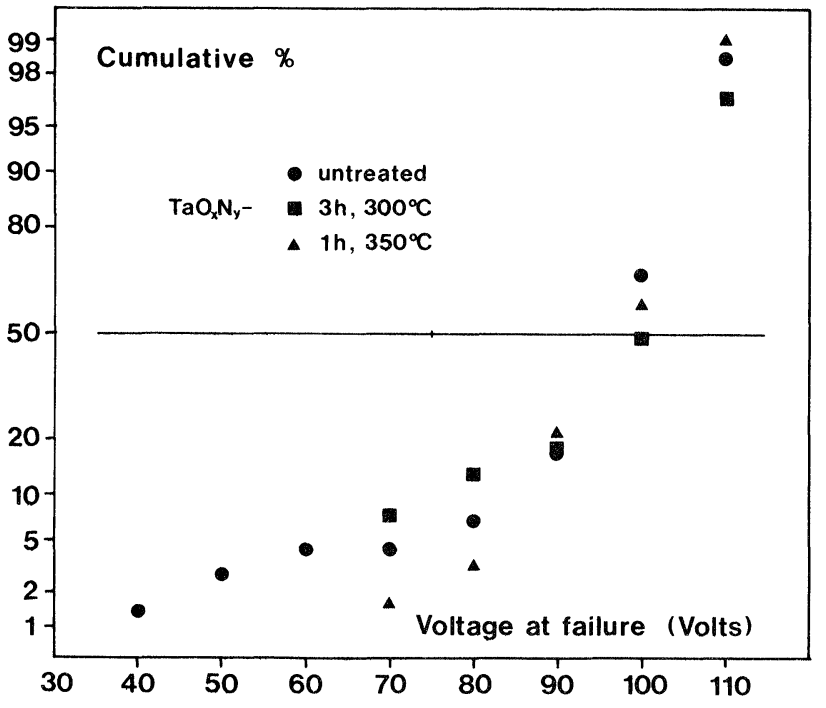

FIGURE 11 Step stress failures at $85^{\circ} \mathrm{C}$ of Ta based counterelectrode capacitors.

\section{CONCLUSION}

Capacitors exhibiting excellent a.c. and d.c. electrical properties have been obtained from triode sputtered thin films of nitrogen doped Tantalum.

A Ta oxinitride layer sputtered onto the dielectric and left as a part of the counterelectrode structure does not degrade the capacitor characteristics or their repeatability.

Both $\mathrm{NiCr}-\mathrm{Au}$ and $\mathrm{Ta}$ based counterelectrode capacitors can withstand temperatures as high as $350^{\circ} \mathrm{C}$, but optimum results have been obtained by heat treating for 3 hours at $300^{\circ} \mathrm{C}$; the temperature stability of the dissipation factor is the parameter most affected by high temperatures. On the basis of these results, the fabrication process of high stability $\mathrm{RC}$ circuits can be simplified, in that the capacitors counterelectrodes, resistors and conductors can be obtained from a single multilayer.

\section{ACKNOWLEDGMENTS}

The authors wish to acknowledge the assistance of Mr. G. Galimberti, Mr. C. Villa, Miss. M. E. Gironi and the staff of S.T.Av. for their valid help in editing this paper.

\section{REFERENCES}

1. H. Y. Kumagay, I. M. Fletcher, C. A. Steidel, K. L. Baurle, and J. R. Hightower, Proc. 23rd Elec. Comp. Conf. (1973) 257.

2. W. Anders, Thin Solid Films 27 (1975) 135.

3. R. D. Huttemann, I. M. Morabito and D. Gerstenberg, IEEE Trans. PHP-11 (1975) 67.

4. R. W. Berry, P. M. Hall and M. T. Harris, Thin Film Technology Van Nostrand and Princeton (1968) chapter 8.

5. W. H. Orr, D. O. Melroy, R. J. Moore, F. P. Pelletier, W. J. Pendergast and W. H. Yocom, Proc. 20th Elec. Comp. Conf. (1970) 602.

6. M. H. Rottersman, M. J. Bill and D. Gerstenberg, IEEE Trans. CHMT-1 (1978) 137.

7. M. Doken, K. Ohwada, S. Okamoto and T. Kamei, IEEE Trans. CHMT-1 (1978) 187.

8. R. E. Peterson and K. L. Baurle, Proc. 27th Elec. Comp. Conf. (1977) 238.

9. G. P. Ferraris, Thin Solid Films, 24 (1974) 113.

10. R. T. Simmons, P. T. Morzenti, D. M. Smyth and D. Gerstenberg, Thin Solid Films, 23 (1974) 75. 

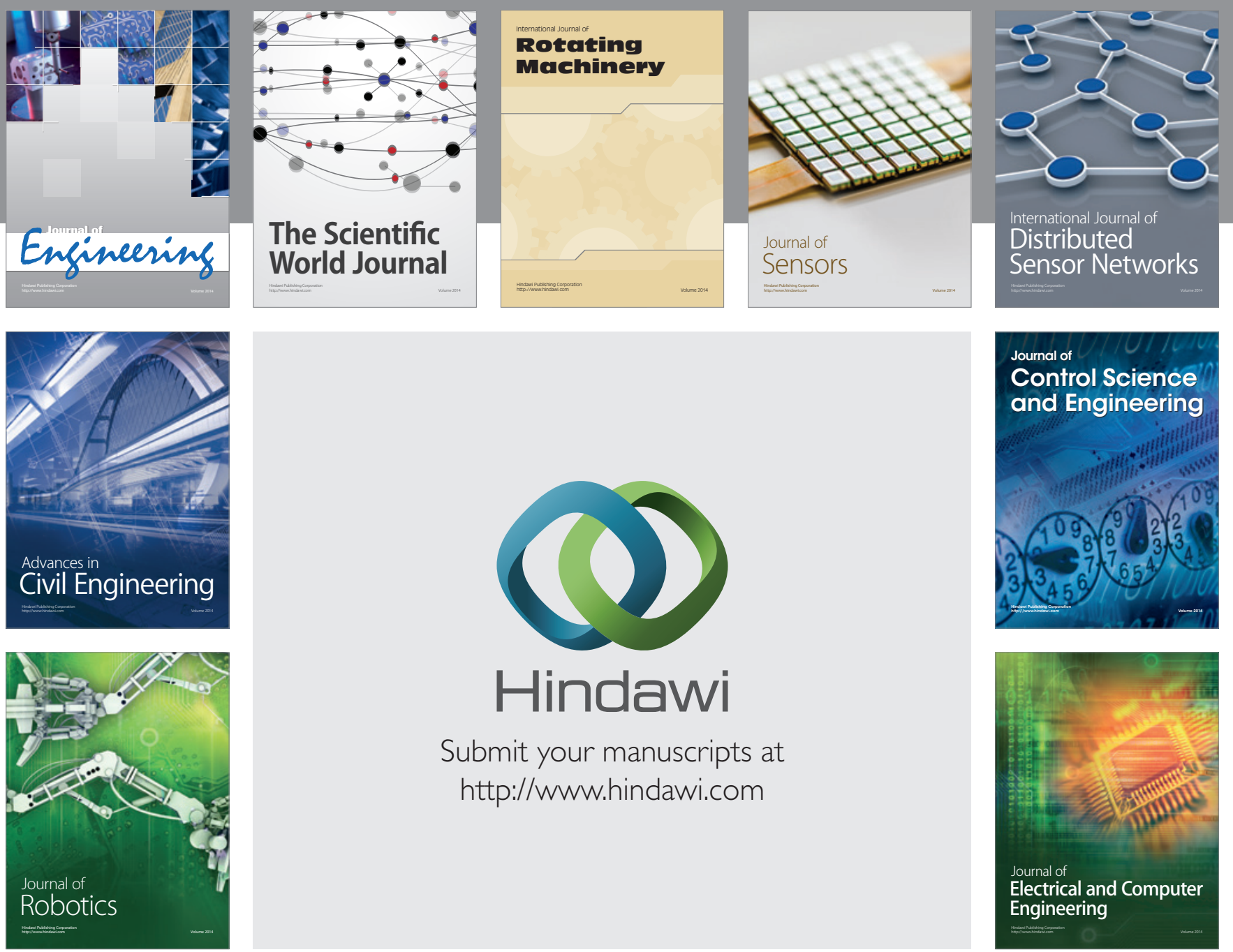

Submit your manuscripts at

http://www.hindawi.com
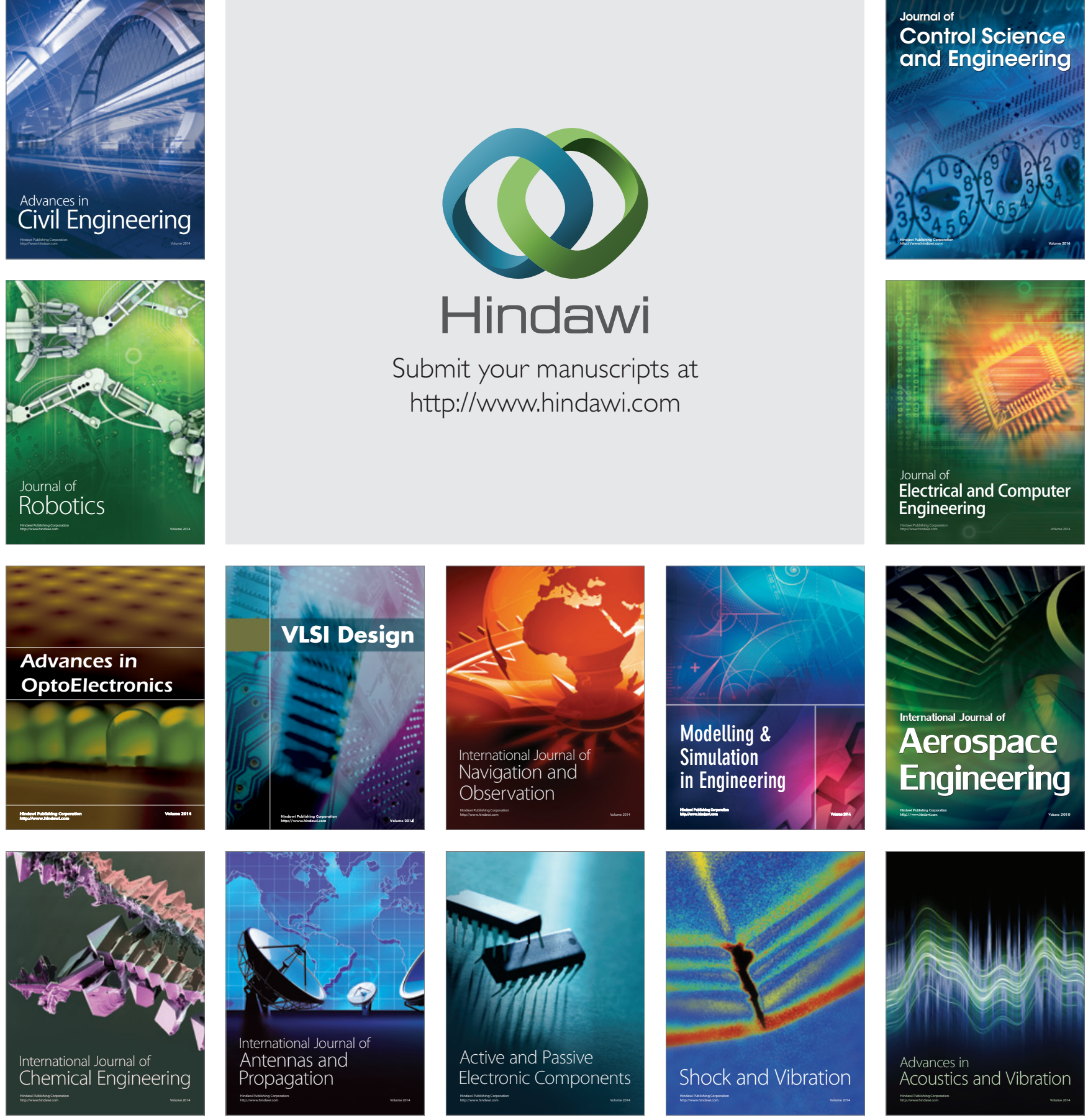